\title{
DIFFERENTIATED PERCEIVED MATCH LOAD AND ITS VARIABILITY ACCORDING TO PLAYING POSITION IN PROFESSIONAL SOCCER PLAYERS DURING AN ENTIRE SEASON
}

\author{
Unai Azcárate' ${ }^{1}$ Javier Yanci ${ }^{2}$, and Asier Los Arcos ${ }^{2}$ \\ 'Physical Education and Sport Department, Faculty of Education and Sport, \\ University of the Basque Country (UPV/EHU), Vitoria-Gasteiz, Spain \\ ${ }^{2}$ Society, Sports and Physical Exercise Research Group (GIKAFIT). \\ Department of Physical Education and Sport. Faculty of Education and Sport. \\ University of the Basque Country (UPV/EHU), Vitoria_Gasteiz, Spain
}

Original scientific paper

DOI: $10.26582 / \mathrm{k} .52 .1 .13$

\begin{abstract}
:
The aims were to assess differentiated perceived match exertion and its variability according to playing position for professional soccer players. Nineteen Spanish players declared their respiratory and muscular perceived exertions (PEs) after official matches during an entire season. Players were classified according to their playing position. In order to assess differentiated perceived match exertion, soccer players were asked to assess their perceived level of exertion following each official match. Considerable differences $(p<.05 ; E S=.41$ to 2.49) were found between some playing positions but not always in both dimensions of PE (respiratory and muscular). Advanced midfielders (AvMs), wide midfielders (WMs) and wing backs (WnBs) reported the highest match respiratory PE and muscular PE scores. Furthermore, match-to-match differentiated perceived match exertion variability ranged from 12.8 to $27.7 \%$ for respiratory perceived exertion and from 11.5 to $25.2 \%$ for muscular perceived exertion according to playing position. Match respiratory-muscular PE differences varied among the playing positions, showing higher muscular PE than respiratory PE in central backs (CBs), WMs and central midfielders $(\mathrm{CMs})(\mathrm{p}<.05$; ES=-.35 to .68), but higher respiratory $\mathrm{PE}$ than muscular PE in wing backs $(\mathrm{p}<.05 ; \mathrm{ES}=-.35)$. Soccer differentiated perceived match exertion is different inter and intra some playing positions, showing large swings for match-to-match variability between playing positions. These facts confirm that the deconstruction of the overall PE provides a more accurate evaluation of the subjective match internal load in some playing positions.
\end{abstract}

Key words: quantification, football, differentiated perceived effort, variation, posts

\section{Introduction}

With classification points on the line, official matches are the most important weekly session of the 9-10 consecutive months that the competitive season lasts. Such is their significance that, in general, weeks turn into the periodization unit of professional soccer coaches, slightly varying the weekly training load (TL) during the competitive period of the season (Los Arcos, MendezVillanueva, \& Martínez-Santos, 2017; Loturco, et al., 2016; Malone, et al., 2015) beyond the length of the between-match microcycles (Azcárate, Los Arcos, \& Yanci, 2018). Taking previous and future matches as a reference, in weeks when only one match was held, professional soccer coaches designed recovery sessions for starting players (i.e. players who participated in the match for at least $45 \mathrm{~min}$ ) at the beginning of the week (Gaudino, et al., 2015; Loturco, et al., 2016; Malone, et al., 2015), planning training activities to attain the highest weekly TL in the middle of the week (Los Arcos, et al., 2017; Malone, et al., 2015; Stevens, De Ruiter, Twisk, Geert, \& Beek, 2017) and reducing physiological and physical demands in training sessions prior to a match (Los Arcos, et al., 2017; Malone, et al., 2015; Thorpe, et al., 2015), in order to prepare players for the competition and avoid pre-match fatigue. During weeks when two matches were played, the internal TL of training sessions was reduced in comparison to weeks with one match, signaling the importance that recovery strategies have in the former (Clemente, et al., 2017) for 
players to be at their top physical shape in each match. Therefore, the match load (ML) seems to determine the distribution of weekly TL.

Besides being the most important part of the week, in comparison to training sessions, matches are the most demanding physical/physiological sessions of the week for starters (Anderson, et al., 2016; Arcos, Yanci, Mendiguchia, \& Gorostiaga, 2014; Los Arcos, et al., 2017). Despite the fact that many studies have described external and internal ML measured by objective methods, few have quantified internal ML in high-level soccer matches using players' subjective assessments (i.e. match perceived exertion [PE]) (Arcos, et al., 2014; Los Arcos, Mendez-Villanueva, Yanci, \& MartinezSantos, 2016). Recently, due to the substantial differences found between match respiratory PE (PEres) and muscular PE (PEmus) in Spanish young professional soccer players (Los Arcos, et al., 2016) and in Australian Football League players (Weston, Siegler, Bahnert, McBrien, \& Lovell, 2015), differential PE (dPE) has been suggested for the assessment of the match-imposed internal ML (Los Arcos, et al., 2016; McLaren, Weston, Smith, Cramb, \& Portas, 2015; Weston, et al., 2015) because these measures represent distinct sensory inputs and provide a more accurate evaluation than overall PE (Weston, et al., 2015). However, while external ML-based soccer studies found that ML varied among playing positions (Castellano, Álvarez-Pastor, \& Bradley, 2014; Sarmento, et al., 2014), no study has evaluated the impact of playing positions on professional soccer match dPE.

On the other hand, high match-to-match variability of ML (i.e. external and internal load) is a distinctive feature in soccer (Bush, Archer, Hogg, \& Bradley, 2015; Carling, Bradley, McCall, \& Dupont, 2016; Los Arcos, et al., 2016). Previous studies have found large match-to-match variability for several high-speed running parameters (i.e. $>$ $19.8 \mathrm{~km} \cdot \mathrm{h}^{-1}$ ) in professional soccer players (Bush, et al., 2015; Carling, et al., 2016; Gregson, Drust, Atkinson, \& Salvo, 2010). These studies described a match-to-match variability (coefficient of variation [CV]) from $10.7 \%$ to $32.3 \%$ reported for high-intensity-running variables of distance covered during a match in professional soccer players of the English Premier League (Bush, et al., 2015; Gregson, et al., 2010) and the French Ligue 1 (Carling, et al., 2016). In addition, it was found that this variability differed considerably between playing positions (Bush, et al., 2015; Carling, et al., 2016; Gregson, et al., 2010). Match dPE variability has been assessed in several soccer codes, such as Australian Football (Weston, et al., 2015) and rugby (McLaren, et al., 2015), but this was one occasion in the case of young professional soccer players, in which this variability ranged from $14 \%$ to $54 \%$ depending on the playing time, being lower the longer the players participated (Los Arcos, et al., 2016). However, no study has assessed the match-to-match dPE variability of professional soccer players according to their playing position.

Therefore, the main aim of this study was to assess dPE ML and its variability according to playing position for Spanish professional soccer players during an entire season.

\section{Methods}

\section{Participants}

Match dPE (i.e. PEres and PEmus) data were collected from nineteen male outfielders playing professional soccer $(27.8 \pm 3.1$ years; body height $181.8 \pm 3.3 \mathrm{~cm}$; body mass $76.1 \pm 5.1 \mathrm{~kg}$ ) belonging to the same Spanish Second Division League team during the 2015/2016 season. Goalkeepers were excluded from the study. The participants gave informed consent to take part in this study. The research was conducted according to the Declaration of Helsinki (2013) and received approval from the local Ethics Committee.

\section{Procedures}

In order to assess dPE ML, soccer players were asked to assess their perceived level of exertion in ten minutes following each official match (Los Arcos, Martínez-Santos, Yanci, Mendiguchia, \& Méndez-Villanueva, 2015) using Foster's 0-10 scale (Foster, et al., 2001) and by the same person every time (i.e. fitness coach). This was done for centralrespiratory (PEres) and local-muscular (PEmus) effort (Los Arcos, et al., 2016; Weston, et al., 2015). Players responded to two simple questions on a unique evaluation sheet and always in the same order: How hard was your session on your chest? and How hard was your session on your legs? Each player completed the 0-10 scale randomly without the presence of other players and they could not see the values of other participants. All players became familiarized with this method during the pre-season match period (eight weeks, from July 9 to August 22), in both training sessions and friendly matches. The playing time for each match was recorded for each player, excluding warm-up and half-time rest periods (Los Arcos, et al., 2016; Yanci, MartínezSantos, \& Los Arcos, 2014).

\section{Design}

During the data collection process, players trained 5-6 times (a.m. and/or p.m.) and participated in 1-2 matches (league and cup) per week from the end of August to the beginning of May. PEres and PEmus ML was recorded according to the position of players who played the entire match (i.e. central back [CB], wide back [WB], wing back [WnB], wide midfielder [WM], central midfielder [CM], advanced midfielder [AvM], and 
striker [S]). Matches in which outfielders participated $<90$ minutes (i.e. substitutes and substituted players) were excluded from the study. Furthermore, matches in which players switched positions throughout the match (i.e. mixed position) were also excluded. The team used the same tactical system in all matches (1-3-4-3). Matches in which one or more players were sent off were not included in this research. In total, 44 official matches were considered for data analysis: 22 "home" matches, out of which four were cup and 18 were league matches, and 22 "away" matches, comprising three cup and 19 league matches. A total of 331 individual $\mathrm{PE}$ ratings (mean 17, range 2-34 observations per player) were obtained from 44 of the 50 official matches disputed from team in the season (i.e. 36 of the 42 league matches and seven of the eight King's Cup matches), with the following occurrences for each playing position: $\mathrm{CB}$ position, 40 occurrences from three players; WB position, 79 occurrences from six players; WnB position, 55 occurrences from seven players; WM position, 51 occurrences from six players; $\mathrm{CM}$ position, 33 occurrences from two players; AvM position, 19 occurrences from five players; and S position, 11 occurrences from four players.

\section{Statistical analysis}

Data are expressed as mean \pm standard deviation (SD). For each playing position, matchto-match variability in PEres and PEmus was expressed using the coefficient of variation $(\mathrm{CV}$; \%) (Atkinson \& Nevill, 1998). Additionally, the distribution of the data was measured for each playing position using the Kolmogorov-Smirnov normality test, which showed that data were not normally distributed. The Kruskal-Wallis test and Mann-Whitney U test were used to analyze the between-position comparison regarding intra- and inter-playing position for PEres and PEmus in each case, respectively. Furthermore, intra- and interplaying position practical differences in PEres and PEmus were assessed by calculating the Cohen's $\mathrm{d}$ effect size (Cohen, 1988). Effect sizes (ESs) of higher than $0.8,0.8-0.5,0.5-0.2$ and lower than 0.2 were considered large, moderate, small, and trivial,

Table 1. Match respiratory and muscular perceived exertions (i.e. PEres and PEmus), between-positions comparison and its match-to-match variability according to the playing positions

\begin{tabular}{|c|c|c|c|c|c|c|c|c|}
\hline & CB & WB & WnB & WM & $\mathrm{CM}$ & AvM & $S$ & Differences ( $p$ and ES) between PPs \\
\hline Occ. & 40 & 79 & 55 & 51 & 33 & 19 & 11 & \\
\hline PEres & $5.8 \pm 0.8$ & $6.2 \pm 1.1$ & $7.4 \pm 1.3$ & $7.4 \pm 1.2$ & $5.4 \pm 1.2$ & $7.7 \pm 1.1$ & $6.3 \pm 1.7$ & 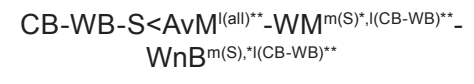 \\
\hline$C V(\%)$ & 12.8 & 18.3 & 17.0 & 16.6 & 22.6 & 13.7 & 27.7 & 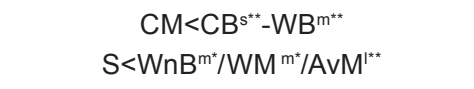 \\
\hline PEmus & $6.5 \pm 1.0$ & $6.2 \pm 1.2$ & $7.0 \pm 1.3$ & $8.1 \pm 0.9$ & $5.8 \pm 0.9$ & $7.8 \pm 1.1$ & $6.8 \pm 1.7$ & 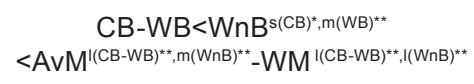 \\
\hline CV (\%) & 15.2 & 19.1 & 18.2 & 11.5 & 15.2 & 13.9 & 25.2 & 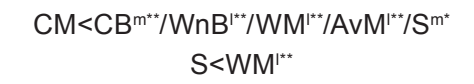 \\
\hline
\end{tabular}

Note. $\mathrm{CB}=$ central back; $\mathrm{WB}=$ wide back; $\mathrm{WnB}=$ wing back $\mathrm{WM}=$ wide midfielder $; \mathrm{CM}=$ central midfielder $; \mathrm{AvM}=$ advanced midfielder; $\mathrm{S}=$ striker; $\mathrm{ES}$ = effect size; PPs = playing positions; Occ. = occurrences; PEres = rating of central-respiratory perceived exertion; PEmus = rating of local-muscular perceived exertion; $\mathrm{CV}=$ coefficient of variation; $-=$ no significant differences; $>=$ significantly higher; $<=$ significantly lower. ${ }^{*}=p<.05 ;{ }^{* *}=p<.001 ; s=$ small ES; $m=$ moderate ES; I = large ES.

Table 2. Respiratory (PEres) vs. muscular (PEmus) match perceived exertion differences by playing positions

\begin{tabular}{lcc}
\hline Playing positions & \multicolumn{2}{c}{ PEres vs. PEmus } \\
\hline All players & $0.35^{*}$ & $\begin{array}{c}\text { Qualitative } \\
\text { interpretation }\end{array}$ \\
Central back & $0.66^{*}$ & small \\
Wide back & 0.06 & trivial \\
Wing back & $-0.35^{*}$ & small \\
Wide midfielder & $0.68^{*}$ & moderate \\
Central midfielder & $0.46^{*}$ & small \\
Advanced midfielder & 0.11 & trivial \\
Striker & 0.32 & small \\
\hline
\end{tabular}

Note. $E S=$ effect size; ${ }^{*}$ significant differences $(p<.05)$ between PEres and PEmus. respectively. The data analysis was presented using the Statistical Package for Social Sciences (version 23.0 for Windows, SPSS ${ }^{\circledR}$ Inc., Chicago, IL, USA). The level of statistical significance was set at $\mathrm{p}<.05$.

\section{Results}

In general, players assessed the dPE of the official match to be "hard" for PEres $(6.5 \pm 0.9)$ and for PEmus $(6.8 \pm 0.8)$, with a match-to-match variability of $13.5 \%$ and $11.8 \%$ for PEres and PEmus, respectively.

According to playing position, dPEs of all official matches ranged from "hard" to "very hard" for PEres (5.4 \pm 1.2 to $7.7 \pm 1.1)$ and for PEmus $(5.8 \pm 0.9$ to $8.1 \pm 0.9$ ), with a CV of 12.8 to $27.7 \%$ for PEres 
and 11.5 to $25.2 \%$ for PEmus (Table 1). The match dPE differences between some playing positions varied according to the dimension of PE assessed.

Considering all players together, significant and substantial differences $(p<.05, E S=$ small $)$ were found between PEres and PEmus, though these differences varied (in significance, magnitude and sign) according to playing position (Table 2).

\section{Discussion and conclusions}

The main aim of the present study was to compare between-position and intra-playing position match PEres and PEmus for Spanish professional soccer players who participated in entire official matches. The main findings were: a) soccer match exertion (i.e. "hard"-"very hard") was different ( $\mathrm{ES}=$ small-large) between some playing positions, but not always in both dimensions of $\mathrm{PE}$ (i.e. respiratory and muscular); b) the variability of playing position match-to-match dPE ranged from 12.8 to $27.7 \%$ for PEres and from 11.5 to $25.2 \%$ for PEmus, with the highest match dPE variability for $\mathrm{CMs}(\mathrm{CV}=15.2-22.6 \%)$ and for $\mathrm{Ss}(\mathrm{CV}=25.2$ $27.7 \%$ ); and c) the dimensions of PE are demanding in different ways and at different levels for some playing positions. Therefore, the deconstruction of the overall PE (i.e. PEres and PEmus) provides a more accurate evaluation of the subjective match internal load for some playing positions, showing substantial between-position and intra-playing position differences according to the dimension of the PE assessed.

Taking together all players, the Spanish Second Division professional soccer players rated all official matches as "hard" $($ PEres $=6.5 \pm 0.9$ and PEmus $=6.8$ \pm 0.8 ). Similarly, young professional soccer players who competed in the Spanish 2nd Division B rated the official match (i.e. $>90 \mathrm{~min}$ ) as "hard," almost "very hard," after the differentiation between PEres (6.7 \pm 1.3$)$ and PEmus (6.9 \pm 1.6$)$ (Los Arcos, et al., 2016). However, elite junior soccer players reported a higher overall PE ( $8.4 \pm 1.3$, "very hard") than professional soccer players after official matches (Wrigley, Drust, Stratton, Scott, \& Gregson, 2012). These results suggest that the degree of difficulty of official matches and, in consequence, ML, is similar in professional soccer players but lower in comparison to junior soccer players. Therefore, previous and post-match training sessions should be periodized according to the competition level of a team. In accordance with the match-to-match variability, dPE was $13.5 \%$ for PEres and $11.8 \%$ for PEmus for all players. These values were lower than the variability described by Los Arcos et al. (2016) in young professional soccer players of an elite reserve team (PEres CV $=18.2 \pm 6.2 \%$; PEmus $\mathrm{CV}=19.4$ $\pm 9.3 \%$ ), suggesting that in addition to the length of the match, shorter playing times were associated with greater variability $(54 \%$ for $<20$-min group and $14 \%$ for $>70$-min group), competition level also affects the variability of the match's degree of difficulty. After quantifying external load (i.e. running demand), several studies also found a high betweenmatch variation in total high-speed running (i.e. $\geq$ $19.8 \mathrm{~km} / \mathrm{h})(\mathrm{CV}=10.7-32.3 \%)$ in European soccer players in high-level leagues (Bush, et al., 2015; Carling, et al., 2016; Gregson, et al., 2010). Therefore, taking into account that ML varies significantly throughout the season, high-level soccer players should be prepared to respond to a high external (i.e. high-speed activity) and internal (i.e. dPE) load variability during the competition.

Moreover, the present study assessed for the first time ever the dPE of professional soccer matches and its variability according to playing position. Interestingly, considerable differences were found between some playing positions, varying depending on the dimension of PE (Ekblom \& Goldbarg, 1971; Hutchinson \& Tenenbaum, 2006) assessed (i.e. PEres and PEmus). In other words, the differences between playing positions did not always arise between both dimensions of PE. These results suggest that, in addition to match playing time (Los Arcos, et al., 2016), playing position also determines the demand of the different dimensions of PE. Moreover, similarly to running demand at high speed (Bush, et al., 2015; Carling, et al., 2016; Gregson, et al., 2010), match-to-match dPE variability was considerably different between playing positions (PEres, $\mathrm{CV}=12.8-27.7 \%$; PEmus, $\mathrm{CV}=11.5-25.2 \%$ ) (Table 1). However, this variability did not coincide with running demand variability. While the highest match-to-match variability measured by running demand (i.e. high-intensity running) was for central defenders in the English Premier League $(\mathrm{CV}=20.8-32.3 \%)$ (Bush, et al., 2015; Gregson, et al., 2010) and for center half players (CV $=19.2-$ 24\%) in the French Ligue 1 (Carling, et al., 2016), the highest match-to-match dPE variability was in our study registered for CMs (22.6-15.2\% in PEres and PEmus) and for Ss (27.7-25.2\% in PEres and PEmus). These differences between studies could be due to the following: use of different methods (i.e. subjective and objective) to quantify ML, the competition level of the players investigated (Bush, et al., 2015), the country of the league and the tactical system (i.e. different playing positions) (Carling, et al., 2015). The results of the present research highlight the importance of assessing dPE ML for each playing position and the need for adaptation to the high match-to-match variability demanded according to the playing position. Therefore, soccer coaches should periodize pre- and post-match training sessions taking into account the playing position of their players.

Previous studies in team sports (Los Arcos, et al., 2016; Weston, et al., 2015) found substantial differences between respiratory and muscular 
efforts in matches, suggesting a more sensitive evaluation of internal load during competitive team sport matches (Weston, 2013), which in turn could help to better inform individualized post-match recovery and training sessions (Weston, et al., 2015). While Los Arcos et al. (2016) found unclear $(E S=-0.17$ \pm 0.63 ; PEmus $>$ PEres) differences between the two dimensions of $\mathrm{PE}$ for young professional soccer players who completed matches, taking together all players of the present study, Spanish $2^{\text {nd }}$ Division players reported a higher PEmus than PEres $(p<.05 ; \mathrm{ES}=0.35$, small). These results suggest that perceived muscular demand is greater than perceived respiratory effort for professional soccer players who complete the match. However, after carrying out a deeper analysis of the PEres-PEmus differences according to playing position, this varied (i.e. in significance, magnitude, and sign). Specifically, higher values of PEmus than PEres were observed in $\mathrm{CB}, \mathrm{WM}$ and $\mathrm{CM}$ positions $(\mathrm{ES}=$ from 0.46 to 0.68 ), while the $\mathrm{WnB}$ position reported greater PEres than PEmus ( $\mathrm{p}<.05 ; \mathrm{ES}=-0.35$, small) (Table 2). Soccer coaches should consider the different demands of match PEres or PEmus for designing specific training programs according to the playing position of their players.

As stated previously, this is the first study that assesses the amount of match respiratory and muscular perceived exertions according to playing positions in professional soccer players. Soccer match exertion is different between playing positions, but not always in both dimensions of PE (i.e. respiratory and muscular). Moreover, the study pointed out the fact that professional soccer players are exposed to a high match-to-match dPE variability that swings between playing positions. Thus, the deconstruction of the overall PE has revealed that different dimensions of PE are demanded in different ways and at different levels for some playing positions. These results confirm that the dPE improves the assessment of the soccer match exertion.

\section{References}

Anderson, L., Orme, P., Di Michele, R., Close, G.L., Milsom, J., Morgans, R., Drust, B., \& Morton, P. (2016). Quantification of seasonal long physical load in soccer players with different starting status from the English Premier League: Implications for maintaining squad physical fitness. International Journal of Sports Physiology and Performance, 11(8), 1038-1046.

Arcos, A.L., Yanci, J., Mendiguchia, J., \& Gorostiaga, E.M. (2014). Rating of muscular and respiratory perceived exertion in professional soccer players. Journal of Strength and Conditioning Research, 28(11), 3280-3288.

Atkinson, G., \& Nevill, A. (1998). Statistical methods for assessing measurement error (reliability) in variables relevant to sports medicine. Sports Medicine, 26(4), 217-238.

Azcárate, U., Los Arcos, A., \& Yanci, J. (2018). Influence of match playing time and the lenght of the between-match microcycle in Spanish professional soccer players' perceived training load. Science and Medicine in Football, 2(1), 23-28.

Bush, M.D., Archer, D.T., Hogg, R., \& Bradley, P.S. (2015). Factors influencing physical and technical variability in the English Premier league. International Journal of Sports Physiology and Performance, 10(7), 865-872.

Carling, C., Bradley, P., Mccall, A., \& Dupont, G. (2016). Match-to-match variability in high-speed running activity in a professional soccer team. Journal of Sports Sciences, 34(24), 2215-2223.

Carling, C., McCall, A., Le Gall, F., \& Dupont, G. (2015). What is the extent of exposure to periods of match congestion in professional soccer players? Journal of Sports Sciences, 33(20), 2116-2124.

Castellano, J., Álvarez-Pastor, D., \& Bradley, P.S. (2014). Evaluation of research using computerised tracking systems (Amisco and Prozone) to analyse physical performance in elite soccer: A systematic review. Sports Medicine, 44(5), 701-712.

Clemente, F., Mendes, B., Nikolaidis, P.T., Calvete, F., Carriço, S., \& Owen, A.L. (2017). Internal training load and its longitudinal relationship with seasonal player wellness in elite professional soccer. Physiology and Behavior, 28(179), 262-267.

Cohen, J. (1998). Statistical power analysis for the behavioral sciences (2 ${ }^{\text {nd }}$ ed.). Mahwah, NJ: Erlbaum Associates.

Ekblom, B., \& Goldbarg, A.N. (1971). The influence of physical training and other factors on the subjective rating of perceived exertion. Acta Physiologica Scandinavica, 83(3), 399-406.

Foster, C., Florhaug, J.A., Franklin, J., Gottschall, L., Hrovatin, L.A., Parker, S., Doleshal, P., \& Dodge, C. (2001). A new approach to monitoring exercise training. Journal of Strength and Conditioning Research, 15(1), 109-115.

Gaudino, P., Iaia, F.M., Strudwick, A.J., Hawkins, R.D., Alberti, G., Atkinson, G., \& Gregson, W. (2015). Factors influencing perception of effort (session rating of perceived exertion) during elite soccer training. International Journal of Sports Physiology and Performance, 10(7), 860-864.

Gregson, W., Drust, B., Atkinson, G., \& Salvo, V. D. (2010). Match-to-match variability of high-speed activities in premier league soccer. International Journal of Sports Medicine, 31(4), 237-242. 
Hutchinson, J.C., \& Tenenbaum, G. (2006). Perceived effort: Can it be considered Gestalt? Physiology of Sport and Exercise, 7(5), 463-476.

Los Arcos, A., Martínez-Santos, R., Yanci, J., Mendiguchia, J., \& Mendez-Villanueva, A. (2015). Negative associations between perceived training load, volume and changes in physical fitness in professional soccer players. Journal of Sports Science and Medicine, 14(2), 394-401.

Los Arcos, A., Mendez-Villanueva, A., \& Martínez-Santos, R. (2017). In-season training periodization of professional soccer players. Biology of Sport, 34(2), 149-155.

Los Arcos, A., Mendez-Villanueva, A., Yanci, J., \& Martinez-Santos, R. (2016). Respiratory and muscular perceived exertion during official games in professional soccer players. International Journal of Sports Physiology and Performance, 11(3), 301-304.

Loturco, I., Nakamura, F.Y., Kobal, R., Gil, S., Pivetti, B., Pereira, L.A., \& Roschel, H. (2016). Traditional periodization versus optimum training load applied to soccer players: Effects on neuromuscular abilities. International Journal of Sports Medicine, 37(13), 1051-1059.

Malone, J., Di Michele, R., Morgans, R., Burgess, D., Morton, J., \& Drust, B. (2015). Seasonal training-load quantification in elite English Premier League soccer players. International Journal of Sports Physiology and Performance, 10(4), 489-497.

McLaren, S.J., Weston, M., Smith, A., Cramb, R., \& Portas, M.D. (2015). Variability of physical performance and player match loads in professional rugby union. Journal of Science and Medicine in Sport, 19(6), 493-497.

Sarmento, H., Marcelino, R., Anguera, M.T., CampaniÇo, J., Matos, N., \& LeitÃo, J.C. (2014). Match analysis in football: A systematic review. Journal of Sports Sciences, 32(20), 1831-1843.

Stevens, T.G.A., De Ruiter, C.J., Twisk, J.W.R., Geert, J.P., \& Beek, P.J. (2017). Quantification of in-season training load relative to match load in professional Dutch Eredivisie football players. Science and Medicine in Football, $1(2), 117-125$.

Thorpe, R.T., Strudwick, A.J., Buchheit, M., Atkinson, G., Drust, B., \& Gregson, W. (2015). Monitoring fatigue during the in-season competitive phase in elite soccer players. International Journal of Sports Physiology and Performance, 10(8), 958-964.

Weston, M. (2013). Difficulties in determining the dose-response nature of competitive soccer matches. Journal of Athletic Enhancement, 2(1), 1-2.

Weston, M., Siegler, J., Bahnert, A., McBrien, J., \& Lovell, R. (2015). The application of differential ratings of perceived exertion to Australian Football League matches. Journal of Science and Medicine in Sport, 18(6), 704-708.

Wrigley, R., Drust, B., Stratton, G., Scott, M., \& Gregson, W. (2012). Quantification of the typical weekly in-season training load in elite junior soccer players. Journal of Sports Sciences, 30(15), 1573-1580.

Yanci, J., Martínez-Santos, R., \& Los Arcos, A. (2014). Respiratory and muscular perceived efforts after official games in professional soccer players. Journal of Strength and Conditioning Research, 28(11), 45-53.

Submitted: January 29, 2018

Accepted: January 7, 2019

Published Online First: May 15, 2020

Corresponding author:

Unai Azcárate, M.Sc.

Faculty of Education and Sport, University of the

Basque Country (UPV/EHU)

Lasarte, s/n, Vitoria-Gasteiz, 01005, Spain.

E-mail: uazcarate001@ikasle.ehu.eus

Telephone: +34945013529

\section{Acknowledgements}

The authors gratefully acknowledge the support of the Spanish government subproject Integration ways between qualitative and quantitative data, multiple case development, and synthesis review as main axis for an innovative future in physical activity and sports research [PGC2018-098742-B-C31] (2019-2021) (Ministerio de Ciencia, Innovación y Universidades, Programa Estatal de Generación de Conocimiento y Fortalecimiento Científico y Tecnológico del Sistema I + D + i), that is part of the coordinated project New approach of research in physical activity and sport from mixed methods perspective (NARPAS_MM) [SPGC201800X098742CV0]. 